CNS Spectrums (2017), 22, 236-245. C Cambridge University Press 2017. This is an Open Access article, distributed under the terms of the Creative Commons Attribution licence (http://creativecommons.org/licenses/by/4.0/), which permits nrestricted re-use, distribution, and reproduction in any medium, provided the original work is properly cited.

\title{
Lurasidone for major depressive disorder with mixed features and anxiety: a post-hoc analysis of a randomized, placebo-controlled study
}

\author{
Joyce Tsai, ' Michael E. Thase, ${ }^{2}$ Yongcai Mao, ' Daisy Ng-Mak, ' Andrei Pikalov, ' and \\ Antony Loebel ${ }^{\text {* }}$
}

${ }^{1}$ Sunovion Pharmaceuticals Inc., Fort Lee, New Jersey, and Marlborough, Massachusetts, USA
${ }^{2}$ Perelman School of Medicine of the University of Pennsylvania, Philadelphia, Pennsylvania, USA

Objective. The aim of this post-hoc analysis was to evaluate the efficacy of lurasidone in treating patients with major depressive disorder (MDD) with mixed features who present with mild and moderate-to-severe levels of anxiety.

Methods. The data in this analysis were derived from a study of patients meeting the DSM-IV-TR criteria for unipolar MDD, with a Montgomery-Åsberg Depression Rating Scale (MADRS) total score $\geq 26$, presenting with two or three protocol-defined manic symptoms, who were randomized to 6 weeks of double-blind treatment with either lurasidone $20-60 \mathrm{mg} /$ day $(n=109)$ or placebo $(n=100)$. Anxiety severity was evaluated using the Hamilton Anxiety Rating Scale (HAM-A). To evaluate the effect of baseline anxiety on response to lurasidone, the following two anxiety groups were defined: mild anxiety (HAM-A $\leq 14)$ and moderate-to-severe anxiety (HAM-A $\geq 15)$. Change from baseline in MADRS total score was analyzed for each group using a mixed model for repeated measures.

Results. Treatment with lurasidone was associated with a significant week 6 change versus placebo in MADRS total score for patients with both mild anxiety $(-18.4$ vs. $-12.8, p<0.01$, effect size $[E S]=0.59)$ and moderate-to-severe anxiety $(-22.0$ vs. $-13.0, p<0.001, E S=0.95)$. Treatment with lurasidone was associated with a significant week 6 change versus placebo in HAM-A total score for patients with both mild anxiety (-7.6 vs. $-4.0, p<0.01, E S=0.62)$, and moderate-to-severe anxiety (-11.4 vs. $-6.1, p<0.0001, E S=0.91)$.

Conclusions. In this post-hoc analysis of an MDD with mixed features and anxiety population, treatment with lurasidone was associated with significant improvement in both depressive and anxiety symptoms in subgroups with mild and moderate-to-severe levels of anxiety at baseline.

Received 12 October 2016; Accepted 12 January 2017; First published online 30 March 2017

Key words: Major depressive disorder, mixed features, atypical antipsychotic, lurasidone, anxiety.

\section{Introduction}

The fifth edition of the Diagnostic and Statistical Manual of Mental Disorders (DSM-5) incorporated a new mixedfeatures specifier in order to permit clinicians to note the

\footnotetext{
* Address correspondence and reprint requests to: Antony Loebel, MD, Sunovion Pharmaceuticals Inc., One Bridge Plaza North, Suite 510 Fort Lee, New Jersey 07024, USA.

(Email: antony.loebel@sunovion.com)

Supported by Sunovion Pharmaceuticals Inc. Registered at (Clinicaltrials.gov), no. NCT01421134.

Dr. Edward Schweizer, of the Paladin Consulting Group, provided editorial and medical writing assistance, which was funded by Sunovion Pharmaceuticals Inc.
}

presence of subthreshold hypomania in patients presenting with a major depressive episode. ${ }^{1}$ The available evidence, largely from clinical study populations, suggests that major depressive disorder (MDD) with mixed features may occur in at least $25 \%$ of patients with major depression. ${ }^{2-12}$

In patients with a diagnosis of MDD, the estimated lifetime prevalence of an anxiety disorder is greater than $35 \% .^{13,14}$ The presence of comorbid anxiety in MDD has been found to be associated with greater illness severity, chronicity, and functional impairment. ${ }^{15-18}$

Preliminary research suggests that patients with a diagnosis of MDD with mixed features (subthreshold hypomania) may have rates of anxiety comorbidity in the range of $45-65 \% .^{3,11} \mathrm{MDD}$ with mixed features is also 
associated with higher severity of concurrent anxiety symptoms. ${ }^{10-12}$

High levels of anxiety have frequently been reported to reduce the likelihood of achieving an adequate antidepressant response in patients with both unipolar $\mathrm{MDD}^{19-27}$ and bipolar depression. ${ }^{28-30}$ To our knowledge, no controlled trial to date has evaluated the potential impact of concurrent anxiety symptoms on response to treatment in patients presenting with MDD with mixed features.

Lurasidone is an atypical antipsychotic agent with a high affinity for dopamine $\mathrm{D}_{2}\left(K_{i}=1.7 \mathrm{nM}\right)$ and for the serotonin $5-\mathrm{HT}_{1 \mathrm{~A}},\left(K_{i}=6.7 \mathrm{nM}\right), 5-\mathrm{HT}_{2 \mathrm{~A}}\left(K_{i}=2.0 \mathrm{nM}\right)$, and $5-\mathrm{HT}_{7}$ receptors $\left(K_{i}=0.5 \mathrm{nM}\right){ }^{31}$ Lurasidone has demonstrated efficacy in the treatment of major depressive disorder with mixed features. ${ }^{32}$ Treatment with lurasidone was associated with significant improvement in anxiety symptoms compared with placebo in patients with bipolar depression. ${ }^{33-35}$ The purpose of the present post-hoc analysis was to assess the efficacy of lurasidone in treating MDD patients with mixed features who present with moderate-to-severe levels of anxiety.

\section{Methods}

The data utilized in this post-hoc analysis were based on a study designed to evaluate the efficacy of lurasidone for the treatment of patients with major depressive disorder presenting with subthreshold hypomanic symptoms (mixed features). Briefly, this was a randomized, double-blind, placebo-controlled, 6-week study that enrolled a total of 209 patients at 18 sites in the United States and 26 sites in Europe. Patients assigned to lurasidone received once-daily flexible dosing in the range of $20-60 \mathrm{mg} /$ day. The details of both the design and results of the study are summarized elsewhere. ${ }^{32}$

The diagnosis of major depressive disorder was confirmed with the Structured Clinical Interview for DSM-IV Disorders-Clinical Trial version (SCID-CT), modified to record the presence of mixed symptoms. ${ }^{36}$ Patients were required to have a score $\geq 26$ on the Montgomery-Åsberg Depression Rating Scale $(\mathrm{MADRS})^{37}$ at both the screening and baseline visits. In addition, patients were required to have two or three of the following manic symptoms, on most days for at least 2 weeks prior to screening: elevated or expansive mood, inflated self-esteem or grandiosity, more talkative than usual or pressure to keep talking, flight of ideas or racing thoughts, increased energy, increased or excessive involvement in activities with a high potential for negative consequences, and decreased need for sleep. Patients presenting with irritability, distractibility, and psychomotor agitation could be enrolled; however, consistent with the DSM-5, these nonspecific symptoms were not included in the list of eligible manic symptoms required for study entry.
The study was approved by an institutional review board at each investigational site and was conducted in accordance with the International Conference on Harmonisation of Technical Requirements for Registration of Pharmaceuticals for Human Use's Good Clinical Practice guidelines, and with the ethical principles of the Declaration of Helsinki. An independent data and safety-monitoring board reviewed and monitored patient data throughout the study.

\section{Efficacy assessments}

The primary efficacy endpoint in the study was mean change from baseline to week 6 in MADRS total score. The key secondary efficacy endpoint was mean change from baseline to week 6 in Clinical Global Impression-Severity score (CGI-S), which rates overall illness severity on a 7point scale. ${ }^{38}$ Treatment effect on anxiety was evaluated based on mean change from baseline to week 6 in HAM-A total score. ${ }^{39}$ The HAM-A scale consists of 14 items that evaluate psychic and somatic symptoms of anxiety on a 5point severity scale, ranging from 0 (not present) to 4 (severe), with a total score range of 0 to 56 . The psychic anxiety factor consists of items 1-6, and item 14 on the HAM-A scale; the somatic anxiety factor consists of items 7-13 on the HAM-A scale.

Additional secondary efficacy assessments consisted of the Young Mania Rating Scale (YMRS) ${ }^{40}$ total score and the Sheehan Disability Scale (SDS) total score, which rates the severity of impairment in the following three functional domains: work/study, family, and social. ${ }^{41}$ For patients who had not worked/studied during the week prior to the assessment visit, SDS total score was recorded as "missing," as long as the reason for not working/ studying was not related to the disorder being treated.

\section{Anxiety severity groups}

Patients with baseline HAM-A scores $\geq 15$ were categorized as being in the moderate-to-severe anxiety category; and baseline HAM-A scores $\leq 14$ were categorized as mild anxiety. A score of 14 on the HAM-A has previously been identified as the optimal cutoff for defining moderate or greater levels of anxiety. ${ }^{42} \mathrm{~A}$ separate analysis was not performed for patients with severe anxiety (baseline HAM-A total score $\geq 24$ ) because the sample size $(30 / 208,14.4 \%)$ was small, and analysis results would therefore be unreliable.

\section{Statistical analysis}

Change from baseline in MADRS, CGI-S, and YMRS for lurasidone versus placebo were analyzed for the two baseline anxiety groups (mild and moderate-to-severe) using a mixed model for repeated measures (MMRM), including fixed effects for treatment, visit, anxiety subgroup, and pooled center; baseline score as a 
covariate; and treatment-by-visit, treatment-by-subgroup, subgroup-by-visit, treatment-by-subgroup-byvisit interaction terms. An unstructured covariance matrix was used for within-patient correlation. Endpoint changes in HAM-A and SDS total scores were evaluated based on an analysis of covariance (ANCOVA) of the last observation carried forward (LOCF) data. The ANCOVA model included pooled center, treatment, anxiety subgroup, and treatment-by-subgroup interaction as fixed factors, and each baseline score as a covariate. Since the current analyses were post hoc, and thus exploratory in nature, correction for multiplicity was not made. Effect sizes (Cohen's $d)^{43}$ were calculated as the least-squares mean difference in the change score divided by the pooled standard deviation. Treatment response was defined as a $\geq 50 \%$ reduction from baseline to week 6 in MADRS total score. Remission was defined as a week 6 MADRS total score $\leq 12$. The number needed to treat to achieve response or remission was calculated as the reciprocal of the differences in responder or remitter rates in the lurasidone and placebo groups. ${ }^{44}$

A mediation analysis was performed, using the methodology of Baron and Kenny, ${ }^{45}$ to evaluate the extent to which the antidepressant effect of lurasidone in this MDD/mixed population was mediated by improvement in anxiety severity (the mediating variable). Standardized parameter estimates ( $\beta$ values) with corresponding $p$ values were calculated. The total effect of the relationship between treatment and change in MADRS total score was estimated, and the effect of lurasidone treatment on change in MADRS total score, after controlling for change in HAM-A total score, was estimated. The indirect effect was calculated as the product of the relationship between lurasidone treatment and change in HAM-A $\left(\beta_{2}\right)$, and the relationship between change in HAM-A and change in MADRS $\left(\beta_{3}\right)$. The proportion of the effect that is mediated was calculated as $\left[\beta_{2} \times \beta_{3}\right] / \beta_{1}$. The strength of parameter estimates was interpreted using Kenny's recommendations for estimates of small (0.02), medium (0.15), and large (0.40) effect sizes. ${ }^{46}$ Overall fit of the mediation model was assessed using various global fit indices, including the chi-square test of overall model fit; rootmean-square error of approximation (RMSEA) $<0.06 ;^{47}$ and the Tucker-Lewis Index (TLI) and the Comparative Fit Index $(\mathrm{CFI})>0.90 .^{48}$

\section{Results}

For the overall treatment sample, the mean $(S D)$ MADRS total score was 33.3 (4.2), and the HAM-A total score was 16.9 (6.4). Baseline characteristics were approximately similar for patients with mild versus moderate-to-severe anxiety, except for a somewhat higher proportion of males in patients with mild anxiety (35.6 vs. $26.3 \%$; Table 1 ).
TABLE 1. Baseline demographic and clinical characteristics

\begin{tabular}{lcc} 
Characteristic & $\begin{array}{c}\text { Mild anxiety } \\
\text { (HAM-A } \leq 14 ; \\
n=90)\end{array}$ & $\begin{array}{c}\text { Moderate to } \\
\text { severe anxiety } \\
\text { (HAM-A } \geq 15 ; \\
n=118)\end{array}$ \\
& & \\
& $32(35.6)$ & $31(26.3)$ \\
Male, $n$ (\%) & $46.2(12.3)$ & $44.1(11.8)$ \\
Age, years, mean (SD) & $73(81.1)$ & $106(89.8)$ \\
Race, white, $n$ (\%) & & \\
Current number of mixed features, $n$ (\%) & & \\
$\quad$ Two features & $53(58.9)$ & $77(65.3)$ \\
Three features & $37(41.1)$ & $41(34.7)$ \\
Lifetime number of major depressive & $4.0(3.0)$ & $4.4(4.1)$ \\
$\quad$ episodes, mean (SD) & & \\
Lifetime number of psychiatric & $1.2(1.7)$ & $1.5(2.5)$ \\
$\quad$ hospitalizations, mean (SD) & & \\
Duration of current major depressive & $3.3(2.5)$ & $3.6(2.9)$ \\
episode, months, mean (SD) & & \\
Baseline scores, mean (SD) & & \\
$\quad$ MADRS & $31.9(3.8)$ & $34.3(4.1)$ \\
$\quad$ CGI-S & $4.4(0.6)$ & $4.7(0.6)$ \\
HAM-A & $11.6(2.1)$ & $20.9(5.5)$ \\
YMRS & $10.4(4.5)$ & $10.9(4.5)$ \\
SDS & $19.8(4.5)$ & $20.6(5.5)$ \\
\hline
\end{tabular}

CGI-S = Clinical Global Impression-Severity scale; HAM-A = Hamilton Rating Scale for Anxiety; MADRS = Montgomery-Åsberg Depression Rating Scale; SDS $=$ Sheehan Disability Scale; YMRS = Young Mania Rating Scale.

Mean HAM-A total score in patients with mild and moderate-to-severe anxiety was 11.6 and 20.9, respectively. At baseline, MADRS and HAM-A scores were moderately correlated $(r=0.39)$, while YMRS and HAM-A total scores were minimally correlated $(r=0.17)$.

The mean daily doses of lurasidone in patients with mild and moderate-to-severe anxiety were 37.8 and $35.1 \mathrm{mg}$, respectively. The completion rates in the lurasidone and placebo groups were 93.6 versus $\mathbf{8 0 . 0 \%}$, respectively, in patients with mild anxiety, and 93.5 versus $89.5 \%$, respectively, in patients with moderate-to-severe anxiety.

\section{Efficacy}

\section{MADRS}

Treatment with lurasidone was associated with significantly greater week 6 improvement compared with placebo on MADRS total score in patients with both mild and moderate-to-severe levels of anxiety, with effect sizes of 0.59 and 0.95 , respectively (Table 2 ). In both anxiety subgroups, significantly greater improvement in the MADRS was observed for lurasidone compared with placebo starting at week 3 (Figure 1). For the full-intentto-treat population, the HAM-A total score and the interaction of treatment by HAM-A total score were not significant as covariates in the MMRM model $(p=0.27$ and 0.11 , respectively). Responder rates were significantly higher for lurasidone versus placebo in patients with both 
TABLE 2. Least-squares mean change at week $\mathbf{6}$ in efficacy measures by baseline anxiety severity for lurasidone versus placebo in patients with mild and moderate-to-severe anxiety

\begin{tabular}{|c|c|c|c|c|c|}
\hline & $n$ & $\begin{array}{c}\text { DB baseline, } \\
\text { mean }(S D)\end{array}$ & Mean $(S E)$ change & $p$ value & Effect size \\
\hline \multicolumn{6}{|l|}{ MADRS total } \\
\hline \multicolumn{6}{|c|}{ Moderate-to-severe anxiety } \\
\hline Lurasidone & 61 & $34.2(4.4)$ & $-22.0(1.3)$ & \multirow[t]{2}{*}{$<0.0001$} & \multirow[t]{2}{*}{0.95} \\
\hline Placebo & 57 & $34.5(3.9)$ & $-13.0(1.3)$ & & \\
\hline \multicolumn{6}{|l|}{ Mild anxiety } \\
\hline Lurasidone & 47 & $32.0(4.0)$ & $-18.5(1.4)$ & \multirow[t]{2}{*}{$<0.01$} & \multirow[t]{2}{*}{0.60} \\
\hline Placebo & 43 & $31.8(3.7)$ & $-12.9(1.6)$ & & \\
\hline \multicolumn{6}{|l|}{ CGI-Severity } \\
\hline \multicolumn{6}{|c|}{ Moderate-to-severe anxiety } \\
\hline Lurasidone & 61 & $4.7(0.6)$ & $-2.0(0.1)$ & \multirow[t]{2}{*}{$<0.0001$} & \multirow[t]{2}{*}{0.84} \\
\hline Placebo & 57 & $4.6(0.6)$ & $-1.1(0.2)$ & & \\
\hline \multicolumn{6}{|l|}{ Mild anxiety } \\
\hline Lurasidone & 47 & $4.3(0.6)$ & $-1.6(0.2)$ & \multirow[t]{2}{*}{ n.s. } & \multirow[t]{2}{*}{0.31} \\
\hline Placebo & 43 & $4.5(0.6)$ & $-1.3(0.2)$ & & \\
\hline \multicolumn{6}{|c|}{ HAM-A total ${ }^{\mathrm{a}}$} \\
\hline \multicolumn{6}{|c|}{ Moderate-to-severe anxiety } \\
\hline Lurasidone & 60 & $21.2(5.8)$ & $-11.4(0.9)$ & \multirow[t]{2}{*}{$<0.0001$} & \multirow[t]{2}{*}{0.91} \\
\hline Placebo & 56 & $20.5(5.1)$ & $-6.1(0.9)$ & & \\
\hline \multicolumn{6}{|l|}{ Mild anxiety } \\
\hline Lurasidone & 45 & $11.5(2.1)$ & $-8.2(1.0)$ & \multirow[t]{2}{*}{$<0.01$} & \multirow[t]{2}{*}{0.63} \\
\hline Placebo & 42 & $11.6(2.2)$ & $-4.6(1.1)$ & & \\
\hline \multicolumn{6}{|c|}{ YMRS total } \\
\hline \multicolumn{6}{|c|}{ Moderate-to-severe anxiety } \\
\hline Lurasidone & 61 & $11.6(4.7)$ & $-7.5(0.5)$ & \multirow[t]{2}{*}{$<0.0001$} & \multirow[t]{2}{*}{0.86} \\
\hline Placebo & 57 & $10.2(4.3)$ & $-4.6(0.5)$ & & \\
\hline \multicolumn{6}{|l|}{ Mild anxiety } \\
\hline Lurasidone & 47 & $10.4(4.3)$ & $-6.4(0.5)$ & \multirow[t]{2}{*}{ n.s. } & \multirow[t]{2}{*}{0.28} \\
\hline Placebo & 43 & $10.4(4.7)$ & $-5.4(0.6)$ & & \\
\hline SDS total ${ }^{\mathrm{a}}$ & & & & & \\
\hline Moderate-to-se & & & & & \\
\hline Lurasidone & 36 & $20.3(5.5)$ & $-12.4(1.3)$ & $<0.001$ & 0.80 \\
\hline Placebo & 39 & $21.0(5.3)$ & $-6.6(1.3)$ & & \\
\hline Mild anxiety & & & & & \\
\hline Lurasidone & 34 & $19.4(4.3)$ & $-9.9(1.3)$ & 0.04 & 0.52 \\
\hline Placebo & 30 & $19.9(4.8)$ & $-6.1(1.4)$ & & \\
\hline $\begin{array}{l}\text { Mild anxiety }= \\
\text { Severity scale; HA } \\
\text { Disability Scale; Y } \\
{ }^{\text {a ANCOVA anal }}\end{array}$ & $\begin{array}{l}\leq 14 ; \\
\text { ting } \\
\text { Rati }\end{array}$ & $\begin{array}{l}\text { e-to-severe anxi } \\
\text { Anxiety; MADR } \\
\text {; n.s. = not sig } \\
\text { ndividuals who }\end{array}$ & $\begin{array}{l}\text { AM-A total score } \geq 1 \\
\text { ntgomery-Åsberg De } \\
\text { ployed. }\end{array}$ & $\begin{array}{l}=\text { Clinical } \\
\text { Rating Sca }\end{array}$ & $\begin{array}{l}\text { mpression- } \\
=\text { Sheehan }\end{array}$ \\
\hline
\end{tabular}

mild and moderate-to-severe levels of baseline anxiety, with number needed to treat $(N N T)$ values of 4 and 3 , respectively; remission rates were nonsignificantly higher in patients with mild anxiety, and significantly higher in patients with moderate-to-severe anxiety, with NNT values of 6 and 4, respectively (Figure 2).

\section{$C G I-S$}

Treatment with lurasidone was associated with significantly greater week 6 improvement compared with placebo on CGI-Severity score in patients with moderateto-severe levels of anxiety (Cohen's $d=0.84$ ), but not in those with mild anxiety (Cohen's $d=0.31$; Table 2 ).

\section{$H A M-A$}

For all patients, baseline to week 6 improvement in HAM-A total score was significantly greater for lurasidone compared with placebo (-9.9 vs. $-5.4, p<0.001$, Cohen's $d=0.78$ ), with significant week 6 improvement in favor of lurasidone observed for 6 of 7 items on both the HAM-A psychic and somatic anxiety factors (Figure 3 ).

Treatment with lurasidone was associated with significantly greater week 6 improvement compared with placebo on HAM-A total score in patients with both mild and moderate-to-severe levels of anxiety, with effect sizes of 0.63 and 0.91 , respectively (Table 2). On the HAM-A psychic anxiety factor score, week 6 improvement was 


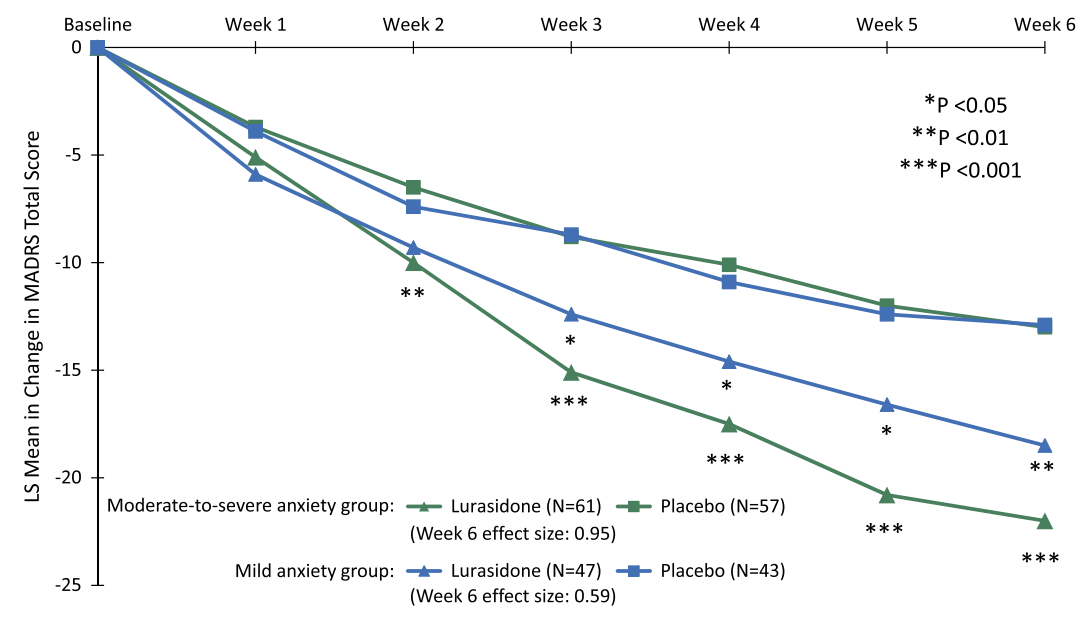

FIGURE 1. Least squares mean change from baseline in MADRS total score for lurasidone versus placebo in patients with mild and moderate-to-severe anxiety.

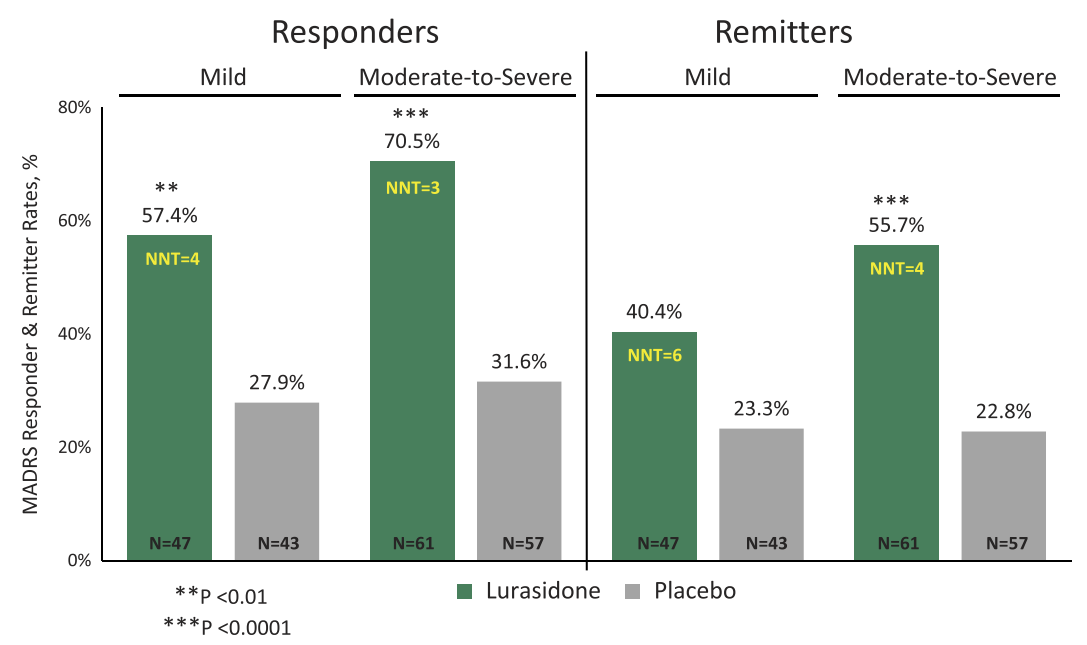

Responder criteria: $\geq 50 \%$ reduction from baseline-to-week 6 in MADRS total score;

Remission criteria: week 6 MADRS total score $\leq 12$; Logistic regression (unadjusted) at LOCF-endpoint

FIGURE 2. MADRS responder and remission rates for lurasidone versus placebo in patients with mild and moderate-to-severe anxiety (LOCF endpoint analysis).

greater for lurasidone versus placebo in patients with both mild (-6.7 vs. $-4.7, p<0.05$, Cohen's $d=0.5)$ and moderate-to-severe (-8.3 vs. $-4.4, p<0.0001$, Cohen's $d=1.0$ ) levels of anxiety. On the HAM-A somatic anxiety factor score, week 6 improvement was greater for lurasidone versus placebo in patients with both mild $(-2.2$ vs. $-0.6, p<0.01$, Cohen's $d=0.7)$ and moderateto-severe (-2.5 vs. $-1.2, p<0.01$, Cohen's $d=0.5)$ levels of anxiety.

\section{Mediation analysis}

Figure 4 summarizes the result of the mediation model, which found a moderate effect for the relationship between treatment with lurasidone and improvement in HAM-A total score $\left(\beta_{2}=-0.29, p<0.0001\right)$, and a large effect for the relationship between improvement in HAM-A total score and improvement in MADRS total score $\left(\beta_{3}=0.73, p<0.0001\right)$. The direct effect of lurasidone on improvement in MADRS total score, after controlling for the effect of the mediator variable (change in HAM-A), was significant but moderate in size $(\beta=-0.14, p<0.01)$. These results are consistent with a substantial degree of mediation, with indirect effects of lurasidone on improvement in MADRS total score accounting for $60.5 \%$ of the total effect and direct effects accounting for $39.5 \%$ of the total effect.

\section{YMRS}

Treatment with lurasidone was associated with significantly greater week 6 improvement on YMRS total score compared with placebo in patients with moderate-tosevere levels of anxiety (Cohen's $d=0.63$ ), but not mild anxiety (Cohen's $d=0.28$; Table 2 ). The proportions of patients reporting the presence of irritability (YMRS item 5 score $\geq 2$ ) were 50.0 and $61.9 \%$ for patients with mild (HAM-A $\leq 14$ ) and moderate-to-severe (HAM-A 


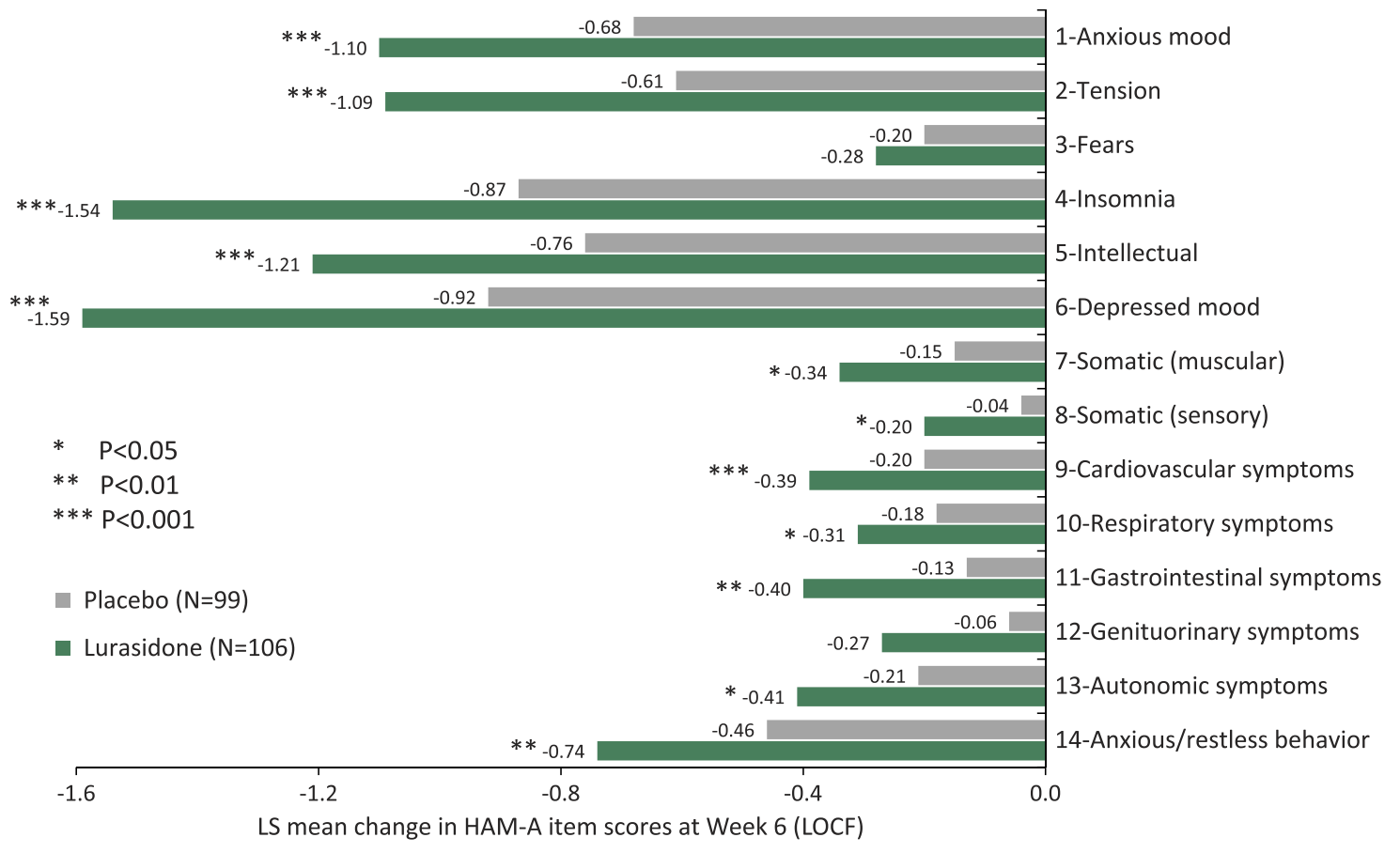

FIGURE 3. Mean baseline to week 6 change in HAM-A item scores (LOCF endpoint analysis).

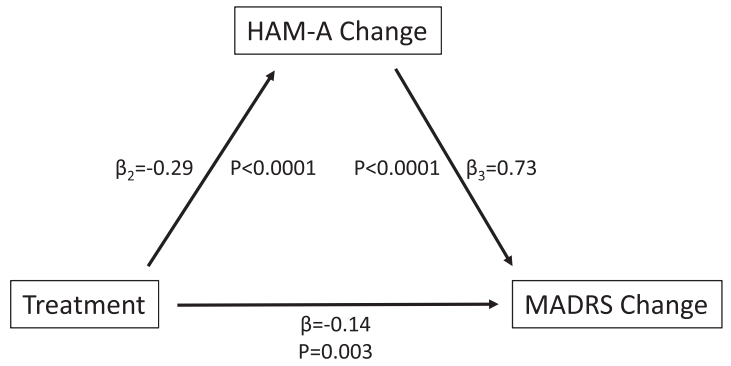

FIGURE 4. Mediation model of the effect of HAM-A change on antidepressant response to lurasidone.

$\geq 15$ ) baseline levels of anxiety, respectively. Similarly, the proportions of patients reporting the presence of psychomotor agitation (YMRS item 2 score $\geq 2$ ) were 31.1 and $39.8 \%$ for patients with mild and moderate-tosevere baseline levels of anxiety, respectively.

\section{$S D S$}

Treatment with lurasidone was associated with significantly greater week 6 improvement compared with placebo on SDS total score in patients with both mild and moderate-to-severe levels of anxiety, with effect sizes of 0.52 and 0.80 , respectively (Table 2 ).

\section{Tolerability}

Overall, the percentage of patients with one or more treatment-emergent adverse events was similar for lurasidone versus placebo in the mild anxiety group
(38.3 vs. $39.5 \%)$ and in the moderate-to-severe anxiety group (41.9 vs. $36.8 \%$ ). The rates of study discontinuation due to an adverse event in the lurasidone and placebo groups were 2.1 vs. $6.7 \%$, respectively, in patients with mild anxiety, and 3.2 versus $3.5 \%$, respectively, in patients with moderate-to-severe anxiety. In patients with mild anxiety, nausea was the only treatment-emergent adverse event that occurred with a frequency $\geq 5 \%$, and more frequently on lurasidone versus placebo (10.6 vs. $4.7 \%$, number needed to harm $[N N H]=17)$. In patients with moderate-to-severe anxiety, two events occurred more frequently on lurasidone versus placebo, somnolence and akathisia ( 6.5 vs. $1.8 \%$ for both events; $\mathrm{NNH}=22$ ).

\section{Discussion}

Mixed features (subthreshold hypomanic symptoms) occur in approximately a third of patients with unipolar 
depression and are associated with greater illness severity, chronicity, and functional impairment compared to pure forms of MDD. ${ }^{2-12}$ In MDD patients without mixed features, the presence of concurrent anxiety has been shown to reduce the likelihood of achieving an adequate antidepressant response. ${ }^{19-27}$ We report here the results of a post-hoc analysis of a placebo-controlled, 6-week trial of MDD presenting with mixed features and anxiety which found that treatment with lurasidone significantly improved depressive symptoms in a subgroup of patients with moderate-to-severe anxiety at baseline. Significant improvement was also noted in the subgroup with mild anxiety at baseline. Effect sizes for lurasidone were notably larger in the moderate-to-severe (vs. mild) anxiety severity subgroup across multiple outcome measures, including MADRS total score (0.95 vs. 0.59), CGI-S (0.84 vs. 0.30$)$, and YMRS (0.63 vs. 0.28$)$.

In the current analysis, $56.7 \%$ of patients with MDD with mixed features presented with moderate-to-severe levels of baseline anxiety. This is comparable to rates previously reported for MDD populations not selected for mixity. ${ }^{13-17}$ Treatment of the current MDD/mixed population with lurasidone was associated with significant improvement in HAM-A total score, with larger effect sizes in the moderate-to-severe (vs. mild) anxiety severity subgroup, and with significant efficacy in treating the psychic and somatic symptoms of anxiety in both anxiety severity subgroups.

The results of a mediation analysis found that a significant proportion $(60.5 \%)$ of the antidepressant effect of lurasidone in this MDD/mixed population was mediated indirectly by improvement in anxiety symptoms. This may in part explain the larger effect sizes observed for endpoint change in MADRS scores in the moderate-to-severe anxiety subgroup.

The presence of comorbid anxiety, or high levels of anxiety symptom severity, has been reported to have a negative effect on antidepressant treatment response in both unipolar and bipolar depression. ${ }^{19-30}$ Notably, treatment with lurasidone has previously demonstrated significant anxiolytic treatment effects in three separate 6-week trials in bipolar depression. ${ }^{33-35}$ While further studies are necessary to confirm these findings, the results of the current analysis, taken together with the consistent improvements in HAM-A scores observed in prior bipolar depression studies, suggest that lurasidone may be a useful treatment for mixed forms of major depression associated with anxiety.

In the current MDD/mixed population, higher levels of anxiety severity at baseline were associated with increased rates of irritability (based on a YMRS item 5 score $\geq 2$ ) and psychomotor agitation (based on a YMRS item 2 score $\geq 2$ ). A significant association between irritability and current and/or prior anxiety has previously been reported in both unipolar ${ }^{49-51}$ and bipolar $^{52}$ depression populations. Increased irritability has also been reported in bipolar patients with comorbid anxiety during inter-episode intervals. ${ }^{53}$

Neither irritability nor anxiety are part of the formal criteria for the DSM-5 diagnosis of MDD with mixed features. However, the high degree of concurrence between irritability and anxiety in the current analysis raises a question as to whether irritability and anxiety are more usefully viewed as core clinical symptoms of MDD with mixed features, or whether (as presently viewed in the DSM-5) they are too nonspecific to qualify as diagnostic criteria. A recent analysis of patients with bipolar depression with mixed features ${ }^{54}$ found that broadening mixed features criteria by including additional, non-DSM-5 symptoms (e.g., irritability, distractibility, agitation) yielded a mixed-depression subgroup that was three times larger than the more restrictive DSM-5 definition. However, this more inclusively defined mixed-depression subgroup had many of the same clinical characteristics as the restrictive DSM-5 subgroup, including higher rates of comorbid anxiety and apparent reduced response to standard antidepressants. $^{55-57}$ The larger effect sizes observed in the moderate-to-severe anxiety subgroup in the current analysis of an MDD with mixed features population, and similarly larger effect sizes in a separate analysis of a subgroup of patients with irritability in this MDD/mixed population (see Swann et al. in the current issue), provide support for the hypothesis that anxiety/irritability symptoms may be clinical biomarkers of treatment responsivity, and thus are best viewed as core components of the MDD with mixed features presentation.

The receptor binding profile of lurasidone suggests a plausible anxiolytic mechanism of action for the current findings, with high affinity (as a partial agonist) for the serotonin $5-\mathrm{HT}_{1 \mathrm{~A}}$ receptor and (as an antagonist) at $5-\mathrm{HT}_{7}$ receptors, both of which have been implicated as anxiety substrates. ${ }^{31,58-62}$ The observed reduction in anxiety associated with pharmacologic inhibition, or receptor inactivation using knockout mouse models, suggests that both the $5-\mathrm{HT}_{1 \mathrm{~A}}$ and $5-\mathrm{HT}_{7}$ receptors may mediate anxiety symptoms and behaviors. ${ }^{58,62}$

Previous studies have reported that the presence of prominent anxiety in MDD was associated with increased illness severity and functional impairment. ${ }^{15-18}$ In the current analysis, there were minimal differences between patients in the moderate-to-severe and mild anxiety severity subgroups on measures of global illness severity (CGI-S) and functional impairment (SDS self-ratings) at study baseline. SDS disability ratings were in the markedly impaired range at baseline for both anxiety severity subgroups, which may reflect the high degree of severity intrinsic to the MDD/mixed features diagnosis. $^{2,4,12}$ Treatment with lurasidone was associated with significant endpoint improvement in SDS impairment 
ratings, with moderate to large effect sizes in patients with both mild and moderate-to-severe anxiety severity.

Baseline anxiety severity appeared to have minimal impact on the tolerability of lurasidone treatment. Rates of discontinuation due to an adverse event were similar for lurasidone (vs. placebo) in the moderate-to-severe anxiety subgroup (3.2 vs. $3.5 \%$, respectively), and in the mild anxiety subgroup (2.1 vs. 6.7\%, respectively). Adverse event rates were similarly low in both anxiety severity subgroups.

The current findings are limited by the post-hoc nature of the analysis, and therefore require confirmation in future studies. Patients were not specifically selected for the presence of moderate-to-severe anxiety, and it is possible that anxiety symptom severity in the current study was lower than the severity of anxiety observed in naturalistic populations of MDD patients presenting with mixed features. In addition, it is possible that anxiety severity assessments were influenced by the presence of irritability and/or agitation in some patients. Patients with a comorbid primary axis I anxiety disorder were excluded from study entry, so that the current results may not be generalizable to depressed patients with severe syndromic levels of anxiety comorbidity. HAM-A ratings were obtained at baseline and at week 6 ; therefore, no information is available on the temporal pattern of improvement in anxiety symptom severity over the 6-week study.

In this post-hoc analysis of an MDD with mixed features and anxiety study population, treatment with lurasidone was associated with significant improvement in both depressive and anxiety symptoms in subgroups with mild and moderate-to-severe levels of anxiety at baseline.

A mediation analysis indicated that improvement in depressive symptom severity on lurasidone was partially mediated by improvement in anxiety. Given the high rates of anxiety reported in patients with a diagnosis of MDD with mixed features, the combined antidepressant and anxiolytic efficacy of lurasidone makes it a potentially useful treatment option in this common and difficult-to-treat clinical population.

\section{Disclosures}

Drs. Tsai, Mao, Ng-Mak, Pikalov, and Loebel are employees of Sunovion Pharmaceuticals Inc. Dr. Thase reports grants and other from Sunovion Pharmaceuticals Inc. during the conduct of the study; grants and other from Alkermes; grants and other from Forest Laboratories (an Allergan affiliate); grants from the National Institute of Mental Health; grants and other from Otsuka; grants from PharmaNeuroboost; grants from Roche; other from Astra-Zeneca; other from BristolMyers Squibb; other from Cerecor; other from Eli Lilly; other from the Gerson Lehman Group; other from GlaxoSmithKline; other from Guidepoint Global; other from Lundbeck; other from MedAvante; other from Merck; other from Neuronetics; other from Novartis; other from Ortho-McNeil Pharmaceuticals; other from Pamlab; other from Pfizer; other from Shire; other from Takeda; other from the American Psychiatric Association; other from Guilford Publications; other from Herald House; other from W.W. Norton \& Companyall outside the submitted work.

\section{REFERENCES:}

1. American Psychiatric Association. Diagnostic and Statistical Manual of Mental Disorders, 5th ed. Washington, DC: American Psychiatric Association; 2013.

2. Judd LL, Akiskal HS. The prevalence and disability of bipolar spectrum disorders in the US population: re-analysis of the ECA database taking into account subthreshold cases. J Affect Disord. 2003; 73(1-2): 123-131.

3. Angst J, Cui L, Swendsen J, et al. Major depressive disorder with subthreshold bipolarity in the National Comorbidity Survey Replication. Am J Psychiatry. 2010; 167(10): 1194-1201; Epub ahead of print Aug 16. https://www.ncbi.nlm.nih.gov/pmc/articles/ PMC3145248/. Accessed January 18, 2017.

4. Hoertel N, Le Strat Y, Angst J, et al. Subthreshold bipolar disorder in a US national representative sample. prevalence, correlates, and perspectives for psychiatric nosography. J Affect Disord. 2013; 146(3): 338-347; Epub ahead of print January 18, 2017.

5. Angst J, Azorin JM, Bowden CL, et al. Prevalence and characteristics of undiagnosed bipolar disorders in patients with a major depressive episode: the BRIDGE Study. Arch Gen Psychiatry. 2011; 68(8): 791-798; http://jamanetwork.com/journals/jamapsychiatry/ fullarticle/1107421. Accessed January 18, 2017.

6. Angst J, Gamma A, Bowden CL, et al. Evidence-based definitions of bipolar-I and bipolar-II disorders among 5,635 patients with major depressive episodes in the BRIDGE Study: validity and comorbidity. Eur Arch Psychiatry Clin Neurosci. 2013; 263(8): 663-673; Epub ahead of print Jan 31.

7. Benazzi F. Frequency of bipolar spectrum in 111 private practice depression outpatients. Eur Arch Psychiatry Clin Neurosci. 2003; 253(4): 203-208.

8. Benazzi F, Akiskal HS. Psychometric delineation of the most discriminant symptoms of depressive mixed states. Psychiatry Res. 2006; 141(1): 81-88; Epub ahead of print Nov 28, 2005.

9. Zimmermann P, Brückl T, Nocon A, et al. Heterogeneity of DSM-IV major depressive disorder as a consequence of subthreshold bipolarity. Arch Gen Psychiatry. 2009; 66(12): 1341-1352; http://jamanetwork.com/journals/jamapsychiatry/fullarticle/ 210481. Accessed January 18, 2017.

10. Perlis RH, Uher R, Ostacher M, et al. Association between bipolar spectrum features and treatment outcomes in outpatients with major depressive disorder. Arch Gen Psychiatry. 2011; 68(4): 351-360; https://www.ncbi.nlm.nih.gov/pmc/articles/PMC3794668/. Accessed January 18, 2017.

11. Perugi G, Angst J, Azorin JM, et al. Mixed features in patients with a major depressive episode. the BRIDGE-II-MIX Study. J Clin Psychiatry. 2015; 76(3): e351-e358.

12. McIntyre RS, Soczynska JK, Cha DS, et al. The prevalence and illness characteristics of DSM-5-defined "mixed feature specifier" in adults with major depressive disorder and bipolar disorder: results from the International Mood Disorders Collaborative Project. J Affect Disord. 2014; 172: 259-264; Epub ahead of print Oct 12.

13. Sanderson WC, Beck AT, Beck J. Syndrome comorbidity in patients with major depression or dysthymia: prevalence and temporal relationships. Am J Psychiatry. 1990; 147(8): 1025-1028. 
14. Kessler RC, Chiu WT, Demler O, Merikangas KR, Walters EE. Prevalence, severity, and comorbidity of 12-month DSM-IV disorders in the National Comorbidity Survey Replication. Arch Gen Psychiatry. 2005; 62(6): 617-627; https://www.ncbi.nlm.nih.gov/ pmc/articles/PMC2847357/. Accessed January 18, 2017.

15. Joffe RT, Bagby RM, Levitt A. Anxious and nonanxious depression. Am J Psychiatry. 1993; 150(8): 1257-1258.

16. Clayton PJ, Grove WM, Coryell W, Keller M, Hirschfeld R, Fawcett J Follow-up and family study of anxious depression. Am J Psychiatry. 1991; 148(11): 1512-1517.

17. Brown C, Schulberg HC, Madonia MJ, Shear MK, Houck PR. Treatment outcomes for primary care patients with major depression and lifetime anxiety disorders. Am J Psychiatry. 1996; 153(10): 1293-1300.

18. Fava M, Rush AJ, Alpert JE, et al. Difference in treatment outcome in outpatients with anxious versus nonanxious depression: a STAR $^{*}$ D report. Am J Psychiatry. 2008; 165(3): 342-351; Epub ahead of print Jan 2. http://ajp.psychiatryonline.org/doi/pdf/ 10.1176/appi.ajp.2007.06111868. Accessed January 18, 2017.

19. Tollefson GD, Holman SL, Sayler ME, Potvin JH. Fluoxetine, placebo, and tricyclic antidepressants in major depression with and without anxious features. J Clin Psychiatry. 1994; 55(2): 50-59.

20. Russell JM, Koran LM, Rush J, Hirschfeld RM, et al. Effect of concurrent anxiety on response to sertraline and imipramine in patients with chronic depression. Depress Anxiety. 2001; 13(1): 18-27.

21. Davidson JR, Meoni P, Haudiquet V, Cantillon M, Hackett D. Achieving remission with venlafaxine and fluoxetine in major depression: its relationship to anxiety symptoms. Depress Anxiety. 2002; 16(1): 4-13.

22. Fava M, Uebelacker LA, Alpert JE, Nierenberg AA, Pava JA, Rosenbaum JF. Major depressive subtypes and treatment response. Biol Psychiatry. 1997; 42(7): 568-576.

23. Flint AJ, Rifat SL. Anxious depression in elderly patients: response to antidepressant treatment. Am J Geriatr Psychiatry. 1997; 5(2): 107-115.

24. Papakostas GI, McGrath P, Stewart J, et al. Psychic and somatic anxiety symptoms as predictors of response to fluoxetine in major depressive disorder. Psychiatry Res. 2008; 161(1): 116-120.

25. Howland RH, Rush AJ, Wisniewski SR, et al. Concurrent anxiety and substance use disorders among outpatients with major depression: clinical features and effect on treatment outcome. Drug Alcohol Depend. 2009; 99(1-3): 248-260; Epub ahead of print Nov 5, 2008.

26. Uher R, Dernovsek MZ, Mors O, et al. Melancholic, atypical and anxious depression subtypes and outcome of treatment with escitalopram and nortriptyline. J Affect Disord. 2011; 132(1-2): 112-120; Epub ahead of print Mar 15.

27. De Carlo V, Calati R, Serretti A. Socio-demographic and clinica predictors of non-response/non-remission in treatment-resistant depressed patients: a systematic review. Psychiatry Res. 2016; 240: 421-430; Epub ahead of print May 5.

28. Feske U, Frank E, Mallinger AG, et al. Anxiety as a correlate of response to the acute treatment of bipolar I disorder. Am J Psychiatry. 2000; 157(6): 956-962; http://ajp.psychiatryonline.org/ doi/pdf/10.1176/appi.ajp.157.6.956. Accessed January 18, 2017.

29. Henry C, Van den Bulke D, Bellivier F, Etain B, Rouillon F, Leboyer M. Anxiety disorders in 318 bipolar patients: prevalence and impact on illness severity and response to mood stabilizer. J Clin Psychiatry. 2003; 64(3): 331-335.

30. El-Mallakh RS, Hollifield M. Comorbid anxiety in bipolar disorder alters treatment and prognosis. Psychiatr Q. 2008; 79: 139-150.

31. Ishibashi T, Horisawa T, Tokuda K, et al. Pharmacological profile of lurasidone, a novel antipsychotic agent with potent 5 -hydroxytryptamine $7\left(5-\mathrm{HT}_{7}\right)$ and $5-\mathrm{HT}_{1 \mathrm{~A}}$ receptor activity.
J Pharmacol Exp Ther. 2010; 334(1): 171-181; Epub ahead of print Apr 19. http://jpet.aspetjournals.org/content/334/1/171.long. Accessed January 18, 2017.

32. Suppes T, Silva R, Cucchiaro J, et al. Lurasidone for the treatment of major depressive disorder with mixed features: a randomized, double-blind, placebo-controlled study. Am J Psychiatry. 2016; 173(4): 400-407; Epub ahead of print Nov 10, 2015.

33. Loebel A, Cucchiaro J, Silva R, et al. Lurasidone monotherapy in the treatment of bipolar I depression: a randomized, double-blind, placebo-controlled study. Am J Psychiatry. 2014; 171(2): 160-168; http://ajp.psychiatryonline.org/doi/pdf/10.1176/appi.ajp. 2013.13070984. Accessed January 18, 2017.

34. Loebel A, Cucchiaro J, Silva R, et al. Lurasidone as adjunctive therapy with lithium or valproate for the treatment of bipolar I depression: a randomized, double-blind, placebo-controlled study. Am J Psychiatry. 2014; 171(2): 169-177; http://ajp. psychiatryonline.org/doi/pdf/10.1176/appi.ajp.2013.13070985. Accessed January 18, 2017.

35. Suppes T, Kroger H, Pikalov A, Loebel A. Lurasidone adjunctive with lithium or valproate for bipolar depression: a placebocontrolled trial utilizing prospective and retrospective enrolment cohorts. J Psychiatr Res. 2016; 78: 86-93; Epub ahead of print Mar 31. http://www.journalofpsychiatricresearch.com/article/ S0022-3956(16)30050-4/pdf. Accessed January 18, 2017.

36. First MB, Williams JBW, Spitzer RL, Gibbon M. Structured Clinical Interview for DSM-IV-TR Axis I Disorders, Clinical Trials Version $(S C I D-C T)$. New York: New York State Psychiatric Institute, 2007. https://eprovide.mapi-trust.org/instruments/structured-clinicalinterview-for-dsm-iv-axis-i-disorders. Accessed January 18, 2017.

37. Montgomery SA, Åsberg M. A new depression scale designed to be sensitive to change. Br J Psychiatry. 1979; 134: 382-389.

38. Guy W. Early Clinical Drug Evaluation Assessment Manual for Psychopharmacology. Publication ADM 76-338. Washington, DC: U.S. Department of Health, Education, and Welfare; 1976; P. 218-222. https://archive.org/details/ ecdeuassessmentm1933guyw. Accessed January 14, 2017.

39. Hamilton M. The assessment of anxiety states by rating. Br J Med Psychol. 1959; 32: 50-55.

40. Young RC, Biggs JT, Ziegler VE, et al. A rating scale for mania: reliability, validity, and sensitivity. Br J Psychiatry. 1978; 133: 429-435.

41. Sheehan DV. The Anxiety Disease. New York: Bantam Books; 1983

42. Matza LS, Morlock R, Sexton C, Malley K, Feltner D. Identifying HAM-A cutoffs for mild, moderate, and severe generalized anxiety disorder. Int J Methods Psychiatr Res. 2010; 19: 223-232; Epub ahead of print Aug 18.

43. Rosenthal R. Parametric measures of effect size. In: Cooper H, Hedges LV, eds. Handbook of Research Synthesis. New York: Russell Sage Foundation; 1994. P. 231-244.

44. Citrome L, Ketter TA, Cucchiaro J, et al. Clinical assessment of lurasidone benefit and risk in the treatment of bipolar I depression using number needed to treat, number needed to harm, and likelihood to be helped or harmed. J Affect Disord. 2014; 155: 20-27; Epub ahead of print Oct 28, 2013.

45. Baron RM, Kenny DA. The moderator-mediator variable distinction in social psychological research: conceptual, strategic, and statistical considerations. J Pers Soc Psychol. 1986; 51(6): 1173-1182.

46. Kenny DA, Judd CM. Power anomalies in testing mediation. Psychol Sci. 2014; 25(2): 334-339; Epub ahead of print Dec 5, 2013. http:// journals.sagepub.com/doi/pdf/10.1177/0956797613502676. Accessed January 18, 2017.

47. MacCallum RC, Browne MW, Sugawara HM. Power analysis and determination of sample size for covariance structure modeling. Psychol Methods. 1996; 1(2): 130-149; http://ww.w.statpower.net/ 
Content/312/Handout/MacCallumBrowneSugawara96.pdf. Accessed January 18, 2017.

48. $\mathrm{Hu} \mathrm{L}$, Bentler PM. Cutoff criteria for fit indexes in covariance structure analysis: conventional criteria versus new alternatives. Struct Equ Modeling. 1999; 6(1): 1-55.

49. Perlis RH, Fraguas R, Fava M, et al. Prevalence and clinical correlates of irritability in major depressive disorder: a preliminary report from the Sequenced Treatment Alternatives to Relieve Depression Study. J Clin Psychiatry. 2005; 66(2): 159-166; quiz 273-274.

50. Perlis RH, Fava M, Trivedi MH, et al. Irritability is associated with anxiety and greater severity, but not bipolar spectrum features, in major depressive disorder. Acta Psychiatr Scand. 2009; 119(4): 282-289; Epub ahead of print Feb 5. https://www.ncbi.nlm. nih.gov/pmc/articles/PMC3312008/Accessed January 18, 2017.

51. Judd LL, Schettler PJ, Coryell W, Akiskal HS, Fiedorowicz JG. Overt irritability/anger in unipolar major depressive episodes: past and current characteristics and implications for long-term course. JAMA Psychiatry. 2013; 70(11): 1171-1180; http://jamanetwork.com/ journals/jamapsychiatry/fullarticle/1737169. Accessed January 18, 2017.

52. Yuen LD, Miller S, Wang PW, et al. Current irritability robustly related to current and prior anxiety in bipolar disorder. J Psychiatr Res. 2016; 79(1): 101-107; Epub ahead of print Jul 30. https://www. ncbi.nlm.nih.gov/pmc/articles/PMC4967068/Accessed January $18,2017$.

53. MacQueen GM, Marriott M, Begin H, Robb J, Joffe RT, Young LT. Subsyndromal symptoms assessed in longitudinal, prospective follow-up of a cohort of patients with bipolar disorder. Bipolar Disord. 2003; 5(5): 349-355.

54. Kim H, Kim W, Citrome L, et al. More inclusive bipolar mixed depression definition by permitting overlapping and nonoverlapping mood elevation symptoms. Acta Psychiatr Scand. 2016; 134(3): 199-206; Epub ahead of print May 2.
55. Smith DJ, Forty L, Russell E, et al. Sub-threshold manic symptoms in recurrent major depressive disorder are a marker for poor outcome. Acta Psychiatr Scand. 2009; 119(4): 325-329; Epub ahead of print Dec 16, 2008.

56. Dudek D, Rybakowski JK, Siwek M, et al. Risk factors of treatment resistance in major depression: association with bipolarity. J Affect Disord. 2010; 126(1-2): 268-271; Epub ahead of print Apr 8.

57. O’Donovan C, Garnham JS, Hajek T, Alda M. Antidepressant monotherapy in pre-bipolar depression; predictive value and inherent risk. J Affect Disord. 2008; 107(1-3): 293-298; Epub ahead of print Sep 12, 2007.

58. Hedlund $\mathrm{PB}$. The $5-\mathrm{HT}_{7}$ receptor and disorders of the nervous system: an overview. Psychopharmacology (Berl.). 2009; 206(3): 345-354; https://www.ncbi.nlm.nih.gov/pmc/articles/ PMC2841472/. Accessed January 18, 2017.

59. Stiedl O, Pappa E, Konradsson-Geuken Å, Ögren SO. The role of the serotonin receptor subtypes $5-\mathrm{HT}_{1 \mathrm{~A}}$ and $5-\mathrm{HT}_{7}$ and its interaction in emotional learning and memory. Front Pharmacol. 2015; 6: 162. https://www.ncbi.nlm.nih.gov/pmc/articles/PMC4528280/ Accessed January 18, 2017.

60. Popova NK, Naumenko VS. $5-\mathrm{HT}_{1 \mathrm{~A}}$ receptor as a key player in the brain 5-HT system. Rev Neurosci. 2013; 24(2): 191-204.

61. Altieri SC, Garcia-Garcia AL, Leonardo ED, Andrews AM. Rethinking 5- $\mathrm{HT}_{1 \mathrm{~A}}$ receptors: emerging modes of inhibitory feedback of relevance to emotion-related behavior. ACS Chem Neurosci. 2013; 4(1): 72-83; Epub ahead of print Dec 20, 2012. https://www.ncbi.nlm.nih.gov/pmc/articles/PMC3547474/ Accessed January 18, 2017.

62. Toth M. Use of mice with targeted genetic inactivation in the serotonergic system for the study of anxiety. In: Chattopadhyay A, ed. Serotonin Receptors in Neurobiology. CRC Press; 2007. Chap 9. https:// www.ncbi.nlm.nih.gov/books/NBK5204/. Accessed January $18,2017$. 